IOSR Journal of Pharmacy

ISSN: 2250-3013, www.iosrphr.org

Volume 2 Issue 5 \|ा| Sep-Oct. 2012 || PP.27-34

\title{
Metoclopramide - nitrite reaction. Validation of its application to the spectrophotometric analysis of generic tablets
}

\author{
Mario R. Delfino (h) ${ }^{1}$, Celina M. Monzón ${ }^{1}$, Silvia R. Hernández ${ }^{2}$ \\ María del C. Sarno ${ }^{1}$ \\ ${ }^{1}$ School of Exact and Natural Sciences. Northeastern National University (UNNE) \\ Instrumental Analysis Laboratory. Av. Libertad 5460 - Corrientes - Argentina \\ ${ }^{2}$ School of Biochemistry and Biological Sciences. Litoral National University (UNL). \\ Analytical Chemistry I Cathedra. Paraje "El Pozo"- Santa Fe - Argentina
}

\begin{abstract}
A quantitative method based on the product of the reaction between the antiemetic metoclopramide and sodium nitrite in acidic medium by visible spectrophotometry is proposed. Cooling or coupling stage are unnecessary, due to the stability of the colored diazo compound, which has a maximum absorbance at $380 \mathrm{~nm}$. This procedure was applied to pharmaceutical formulations containing metoclopramide as single drug. Analytical validation of the proposed method compared to the reference method, HPLC $-U V$ was performed. The parameters of specificity, precision $(C V=0.994 \%$ and $1.58 \%$ for repeatability and intermediate precision respectively), accuracy (recovery between 98.50 to 101.33\%), linearity and linear range obtained, fall within the values established by the British Pharmacopoeia, USP and Argentinian pharmacopoeia.
\end{abstract}

Keywords-Antiemetic, generic tablets, metoclopramide, spectrophotometric method, validation.

\section{INTRODUCTION}

As can be seen in its molecular structure (Fig 1) metoclopramide, 4-amino-5-chloro-N-[2 (diethylamino) ethyl]-2-methoxybenzamide, (MCP), characterized as weak base [1-5] has a wide range of clinical applications in fields as diverse as gastroenterology, surgery, gynecology, radiology and cardiology. It exerts antiemetic effects, stimulating peristaltic emptying and gastrointestinal adjuvant. It is well absorbed when administered orally. It suffers very little transformation at the liver and plasmatic half-life is 2.6 to 6 hours in patients with normal renal function [6]. Metoclopramide hydrochloride is commonly used in prevention and relief of nausea and vomiting. Moreover, it is used in combination with chemotherapy, where drugs such as cisplatin, and other cytotoxic agents, are highly emetic [7].<smiles>CCN(CC)CCNC(=O)c1cc(Cl)c(N)cc1OC</smiles>

Figure 1: Molecular structure of metoclopramide

The British Pharmacopoeia [1], the U.S. Pharmacopoeia [2] and Argentinian Pharmacopoeia [3] establish high performance liquid chromatography (HPLC) with UV detection at $215 \mathrm{~nm}$ as quantitative assay method for the quality control of the tablets of MCP.

The great therapeutic importance of MCP in both clinical and experimental medicine has resulted in extensive literature on its determination in biological fluids and dosage forms, alone or in mixtures with other drugs; by HPLC [8], electron-capture gas chromatography [9], voltammetry [10-11], potentiometry [12] chemiluminescence spectrometry [13-16], fluorimetry[17], UV-spectrophotometry [18] or flow-injection spectrophotometry [19-20]. But some of the reported procedures are not simple for routine analysis and involve expensive experimental setup.

The determination of this drug by spectrophotometric methods has been proposed based on the formation of ion-pair complexes [21-22] and charge-transfer complexes [23-24]. 
A large set of methods is founded on diazotization of the aryl primary amine of MCP with $\mathrm{NaNO}_{2}$ in acidic medium and the formation of a colored dye by the coupling reaction between various coupling agents: sodium dibenzoilmetane [25]; p-dimethylaminocinnamaldehyde [26]; imipramine hydrochloride [27] diphenylamine [28] acetyl acetone [29] N-(1-naphthyl)- ethylenediamine [30] p-nitroaniline [31-32] and $\alpha$ naphthylamine [33]. The main difficulty is that solutions of nitrite are unstable and have to be stored in the refrigerator and frequently replaced, and it is necessary to attach the diazo compound to molecules that confer stability.

For routine quality control, a simple, rapid and sensitive spectrophotometric method is highly desirable. The proposed application uses nitrate solutions for in situ conversion into nitrite thus avoiding problems associated with nitrite oxidation. The nitrite generated is used as a chromogenic agent, obtaining a stable diazo compound at room temperature, which absorbs at $380 \mathrm{~nm}$. Color stability is maintained for more than 2 hours, a period that exceeds the time required for their spectrophotometric reading.<smiles>CCN(CC)CCNC(=O)c1cc(Cl)c(N)cc1OCC(=O)OOc1cc([N+](=O)[O-])c(Cl)cc1OC</smiles>

Figure 2: Diazotization of MCP whit HONO

Validation was performed. This process led to the quantification of MCP as major component in bulk and finished pharmaceuticals, therefore it is included in category I [1-3; 34]. Analytical attributes of accuracy, precision, specificity, linearity and linear range were determined.

The Pharmaceutical Plant of Corrientes (PLAMECOR), under the Ministry of Public Health of the province, produces MCP $10 \mathrm{mg}$ tablets. These are distributed without cost in public hospitals and primary health centers.

The aim of the present work is to provide a simple, accurate, precise and inexpensive method for the assay of MCP performing the steps leading to its validation in bulk and pharmaceutical generic formulations compared to HPLC, in the presence of common excipients.

\subsection{Reagents and Samples}

\section{EXPERIMENTAL}

- Metoclopramide hydrochloride, active ingredient. Lot M102271. Origin: India. 99.8\% purity

- Metoclopramide hydrochloride, $10 \mathrm{mg}$ tablets, elaborated by PLAMECOR. Lot 039.

- Excipients: white precompressed powder (80\%), fumed silica (1.00\%), and talc $(2.00 \%)$.

- Sodium nitrite, analytical reagent grade. Cicarelli (Argentina)

- Anhydrous sodium acetate, analytical reagent grade. Biopack (Argentina)

- Tetramethylammonium hydroxide, 25\% solution. Merck (Germany)

- Hydrochloric acid 38\%, analytical reagent grade. Cicarelli (Argentina)

- Glacial acetic acid, analytical reagent grade. Cicarelli (Argentina)

- Methanol, HPLC grade. Biopack (Argentina)

- Acetonitrile, HPLC grade. Biopack (Argentina)

- Phosphoric acid, analytical reagent grade. Cicarelli (Argentina)

\subsection{Equipment}

- UV-Visible Spectrophotometer Boeco S-26, range 190-900 nm.

- HPLC with variable UV wavelength detector Agilent 1120.

\subsection{Spectrophotometric procedure}

Stock solution of MCP was prepared dissolving an accurately weighted quantity of metoclopramide hydrochloride in distilled water to obtain a solution having a know concentration of $1 \mathrm{mg} / \mathrm{mL}$. Working solutions of hydrochloric acid $6 \mathrm{M}$, and sodium nitrite $0.1 \mathrm{M}$ were prepared. Standards contained aliquots of 1 to $5 \mathrm{~mL}$ of MCP stock solution; $1.0 \mathrm{~mL}$ of hydrochloric acid $6 \mathrm{M}$ and $3.0 \mathrm{~mL}$ of sodium nitrite $0.1 \mathrm{M}$ Blank solution was prepared using the same amount of reactive without MCP solution. Diazotization was carried out at room temperature and cooling was not necessary. These solutions were diluted to $50 \mathrm{~mL}$ with distilled water in a volumetric flask and homogenized. Absorption spectra of the diazo compound showed a maximum at $380 \mathrm{~nm}$. Hence absorbance was recorded as function of concentration at $380 \mathrm{~nm}$. 
From a pool of $20 \mathrm{MCP}$ tablets, an accurately weighted mass of $250.0 \mathrm{mg}$ was dissolved by stirring for 15 minutes in $50 \mathrm{~mL}$ of distilled water. A $15 \mathrm{~mL}$ aliquot was centrifuged. Procedure described above was applied on supernatant.

The concentration of active ingredient in the sample was determined by calibration curve and referred to the average mass of one tablet $(110.7 \mathrm{mg})$.

\subsection{Diazo compound stability}

The stability of the diazo compound was monitored by spectrophotometrical readings of a solution prepared as indicated in the previous item, considering time zero the mixture of reagents and active ingredient, recording readings every $10 \mathrm{~min}$, for a period of $2 \mathrm{~h}$ at room temperature.

\subsection{HPLC-UV procedure}

The method used an RP-18C column of $125 \times 4.5 \mathrm{~mm}$, flow rate of $1.5 \mathrm{~mL} / \mathrm{min}$ and detection at 215 $\mathrm{nm}$. Mobile phase was prepared by dissolving $2.7 \mathrm{~g}$ of sodium acetate in $500 \mathrm{~mL}$ of water, mixed with $500 \mathrm{~mL}$ of acetonitrile, and adding $2 \mathrm{~mL}$ of tetramethylammonium hydroxide solution in methanol (1:5). The solution was stirred, adjusted with glacial acetic acid to a $\mathrm{pH}$ of 6.5 , filtered and sonicated for $10 \mathrm{~min}$.

A stock solution of $1.0 \mathrm{mg} / \mathrm{mL}$ of active ingredient in $0.01 \mathrm{M}$ phosphoric acid was prepared; afterwards an aliquot of this stock solution was quantitatively diluted with $0.01 \mathrm{M}$ phosphoric acid to obtain a $50 \mu \mathrm{g} / \mathrm{mL}$ standard solution.

Sample solution preparation: $150 \mathrm{mg}$ of pool of tablets were weighed, dissolved in $250 \mathrm{~mL}$ of phosphoric acid $0.01 \mathrm{M}$, and stirred for $10 \mathrm{~min}$. An aliquot of $15 \mathrm{~mL}$ was centrifuged for $15 \mathrm{~min}$. Supernatant and standard solution were injected into the HPLC $(50 \mu \mathrm{L})$, recording the signal corresponding to the peak of $\operatorname{MCP}\left(\mathrm{t}_{\mathrm{R}}=2.98^{\prime}\right)$ at $215 \mathrm{~nm}$. $\backslash$

The concentration of MCP in solution of pool of tablets was calculated from the ratio of peak areas according to Equation 1:

$\mathrm{C}_{\text {sample }}=\mathrm{C}_{\text {std }} \cdot \mathrm{A}_{\text {sample }} / \mathrm{A}_{\text {std }}$

\subsection{Spectrophotometric method validation}

2.6.1 Specificity

Specificity is the ability of a method to assess unequivocally the analyte in the presence of many others components, such as impurities, degradation products, matrix compound, etc. [1-3]. Specificity was assed by absorption spectra of reagents; reagents and placebo; and reagents and sample.

\subsubsection{Linearity}

Linearity represents the method's ability to produce results directly proportional to analyte concentration within a given interval. A calibration curve in 0.02 to $0.10 \mathrm{mg} / \mathrm{mL}$ interval was prepared using MCP standard solutions. Each analysis was performed by triplicate. This parameter was set using linear regression.

\subsubsection{Precision}

Precision is the degree of agreement among individual test results when the method is applied repeatedly to multiple aliquots of a homogeneous sample. It is expressed as coefficient of variation, CV, of a series of measurements. The precision shall be considered at two levels: repeatability and intermediate precision.

Repeatability expresses the precision under the same operating conditions in a short time interval. Twelve (12) determinations were conducted on the same sample, with a single operator, same equipment and in the same day and CV was determined.

Intermediate precision expresses the intra-laboratory variations. To evaluate this parameter a single homogeneous sample of one concentration was analyzed, and ratings were made by two analysts on two different days and taking three different aliquots from the sample solution. Global CV was determined

\subsubsection{Accuracy}

Accuracy is the proximity between the experimental results and the actual value. In this paper it was determined by two methods: recovery assay and comparison with the official HPLC- UV method [35].

\subsection{Stability}

\section{RESULTS AND DISCUSSIONS}

After addition of the reagents, the diazo compound reaches maximum intensity immediately at room temperature. The color was stable for a period of more than $2 \mathrm{~h}$ (Fig. 3). 


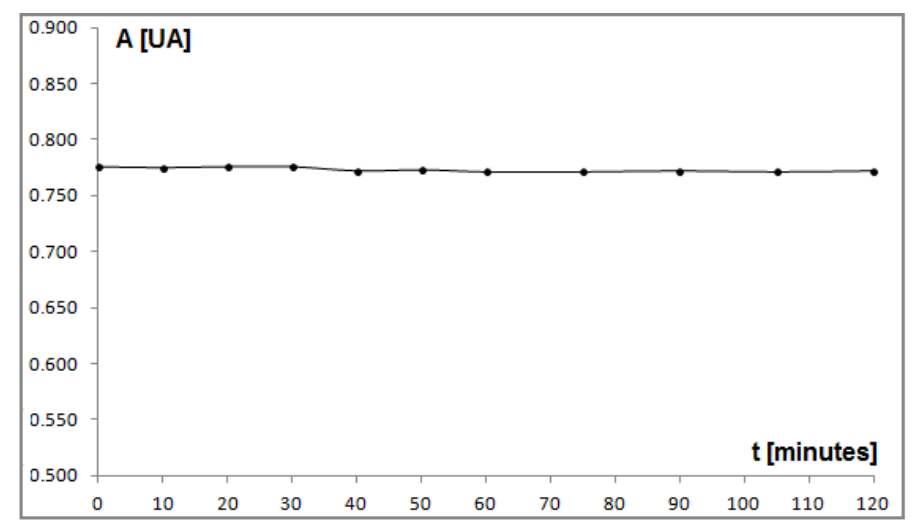

\subsection{Specificity}

Figure 3: Stability of the MCP diazo compound

The absorption spectra of reagents and reagent plus placebo solutions show many similarities between them (Fig. 4). This proves that the excipients that accompany the active ingredient in the formulation are chemically indifferent to the reagents used. The specificity of the method was confirmed.

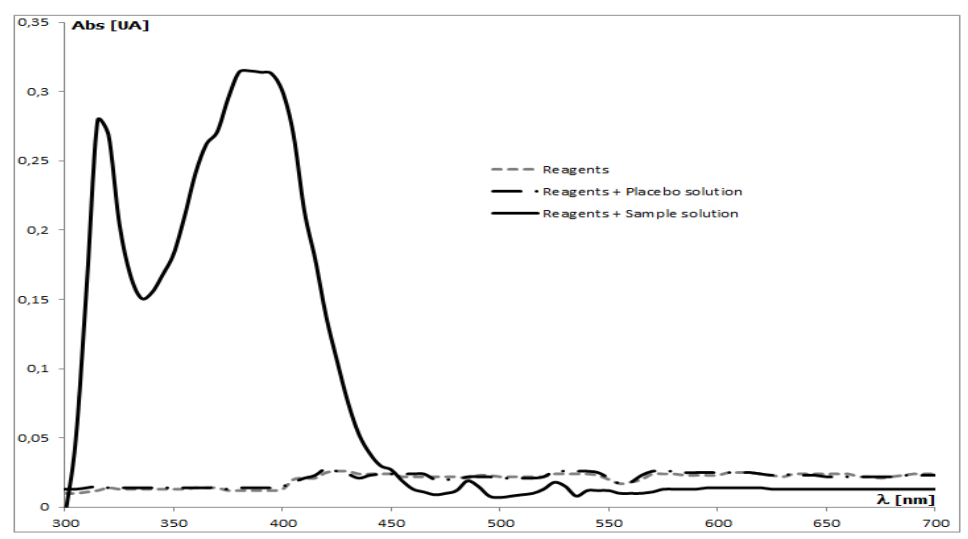

Figure 4: Specificity assay.

\subsection{Linearity}

The method was linear over the range of 0.02 to $0.10 \mathrm{mg} / \mathrm{mL}$ (Fig. 5). It was not necessary to explore the linearity of the response in a lower concentration range as it is quality control of the active ingredient of a drug.

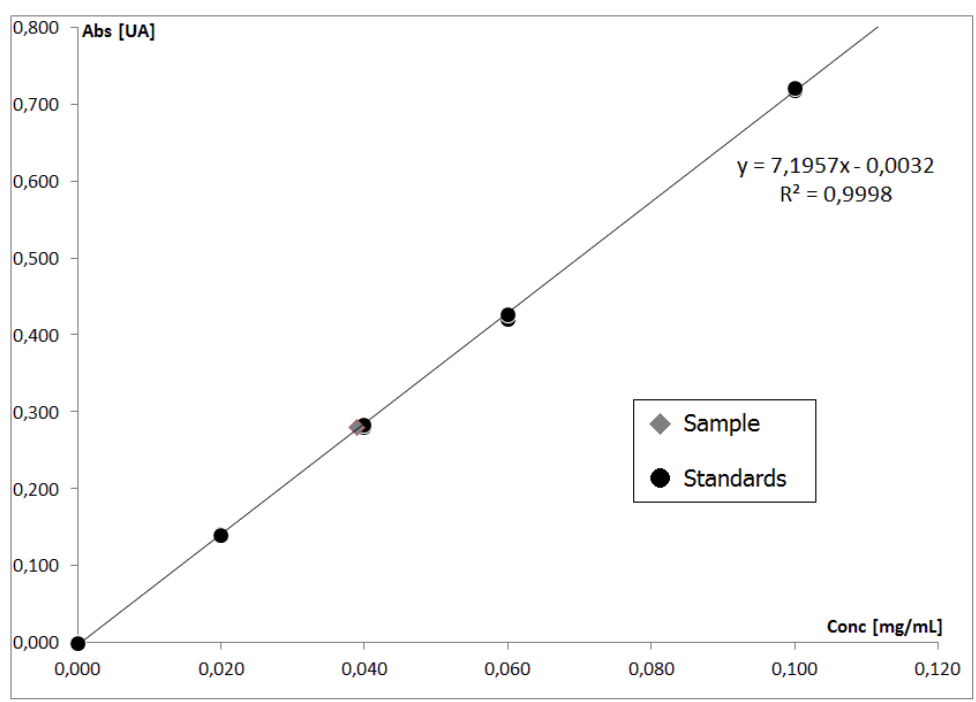


Figure 5: Spectrophotometric method linearity.

The confidence intervals for the intercept and slope were calculated using a Microsoft Excel ® spreadsheet, Table 1 . The interval of the intercept includes the point $(0,0)$ with a confidence level of $95 \%$.

Table 1: Analysis of variance of linear regression to a confidence level of $95 \%(\mathrm{p}=0.05)$

\begin{tabular}{|l|l|}
\hline Adjusted Correlation $\mathrm{R}^{2}$ & 0.9998 \\
\hline Intercept & $0.0022 \pm 0.0032$ \\
\hline Slope & $7.1957 \pm 0.0568$ \\
\hline
\end{tabular}

\subsection{Repeatability.}

According to the procedure described above, twelve sample aliquots were used. Results are shown in Table 2.

Table 2: Repeatability of the proposed method

\begin{tabular}{|l|l|}
$\mathbf{N}^{\circ}$ & Mass recovered \\
\cline { 2 - 2 } & {$[\mathrm{mg}]$} \\
\hline 1 & 9.81 \\
\hline 2 & 10.02 \\
\hline 3 & 10.02 \\
\hline 4 & 9.81 \\
\hline 5 & 9.88 \\
\hline 6 & 9.74 \\
\hline 7 & 9.70 \\
\hline 8 & 9.91 \\
\hline 9 & 9.81 \\
\hline 10 & 9.88 \\
\hline 11 & 9.77 \\
\hline 12 & 9.84 \\
\hline $\mathbf{X}$ & 9.85 \\
\hline SD & 0.098 \\
\hline CV \% & 0.994 \\
\hline
\end{tabular}

The method gives a CV\% of 0.994 ; this is less than $2 \%$, which is required for this type of analytical determinations [1-3].

\subsection{Intermediate Precision}

The study was carried out with spiked samples prepared with three different levels of MCP (5, 10 and $15 \mathrm{mg}$ of active ingredient), following the spectrophotometric method as described. Each analysis was performed by triplicate. The results, expressed as recovered percentage (\%Rec) of MCP, are shown in Table 3. 
Metoclopramide - nitrite reaction. Validation of its application to the spectrophotometric analysis ...

Table 3: Intermediate precision for the spectrophotometric method.

\begin{tabular}{|c|c|c|c|c|c|c|c|}
\hline \multirow{3}{*}{$\begin{array}{l}\text { Mass } \\
\text { adde } \\
\text { d } \\
{[\mathrm{mg}]}\end{array}$} & & \multicolumn{2}{|c|}{ ANALYST 1} & \multicolumn{2}{|c|}{ ANALYST 2} & \multirow{3}{*}{\multicolumn{2}{|c|}{$\begin{array}{l}\text { REPRODUCIBILIT } \\
\text { Y }\end{array}$}} \\
\hline & & DAY 1 & DAY 2 & DAY 1 & DAY 2 & & \\
\hline & & $\%$ Rec & $\%$ Rec & $\% \operatorname{Rec}$ & $\% \operatorname{Rec}$ & & \\
\hline \multirow{6}{*}{5} & & 101.23 & 100.56 & 104.32 & 99.40 & \multirow{6}{*}{$\begin{array}{l}\mathbf{n}= \\
\mathbf{M}= \\
\mathbf{S D}= \\
\mathrm{CV} \%=\end{array}$} & \multirow{6}{*}{$\begin{array}{l}12 \\
101.40 \\
1.50 \\
1.48\end{array}$} \\
\hline & & 102.56 & 102.69 & 102.23 & 100.65 & & \\
\hline & & 100.89 & 101.20 & 102.23 & 98.89 & & \\
\hline & $\mathbf{M}$ & 101.56 & 101.48 & 102.93 & 99.65 & & \\
\hline & SD & 0.88 & 1.09 & 1.21 & 0.91 & & \\
\hline & RSD \% & 0.87 & 1.08 & 1.17 & 0.91 & & \\
\hline \multirow{6}{*}{10} & & 97.46 & 101.22 & 100.95 & 103.65 & \multirow{6}{*}{$\begin{array}{l}n= \\
M= \\
\mathrm{SD}= \\
\mathrm{CV} \%=\end{array}$} & \multirow{6}{*}{$\begin{array}{l}12 \\
100.84 \\
1.83 \\
1.82\end{array}$} \\
\hline & & 99.67 & 102.95 & 99.65 & 102.66 & & \\
\hline & & 100.32 & 100.45 & 98.78 & 102.32 & & \\
\hline & $\mathbf{M}$ & 99.15 & 101.54 & 99.79 & 102.88 & & \\
\hline & SD & 1.50 & 1.28 & 1.09 & 0.69 & & \\
\hline & RSD\% & 1.51 & 1.26 & 1.09 & 0.67 & & \\
\hline \multirow{6}{*}{15} & & 98.56 & 101.47 & 103.56 & 102.45 & \multirow{6}{*}{$\begin{array}{l}\mathbf{n}= \\
\mathrm{M}= \\
\mathrm{SD}= \\
\mathrm{CV} \%=\end{array}$} & \multirow{6}{*}{$\begin{array}{l}12 \\
100.99 \\
1.52 \\
1.50\end{array}$} \\
\hline & & 99.65 & 100.98 & 102.66 & 101.63 & & \\
\hline & & 101.56 & 99.89 & 100.37 & 99.12 & & \\
\hline & $\mathbf{M}$ & 99.92 & 100.78 & 102.20 & 101.07 & & \\
\hline & SD & 1.52 & 0.81 & 1.64 & 1.74 & & \\
\hline & RSD\% & 1.52 & 0.80 & 1.61 & 1.72 & & \\
\hline
\end{tabular}

\begin{tabular}{ll}
\multicolumn{2}{c}{ Global values $(\mathbf{n}=36)$} \\
\hline M & $\mathbf{1 0 1 . 0 8}$ \\
SD & 1.59 \\
CV \% & 1.58 \\
\hline
\end{tabular}

CV\% for intermediate precision study was less than twice the RSD\% of repeatability. Precision evaluated as repeatability and intermediate precision, shows satisfactory results [1-3].

3.6 Accuracy

\subsubsection{Recovery assay}

This assay was performed by triplicate and in three levels of concentration, Table 4. Placebo solutions enriched with different volumes of $1.0 \mathrm{mg} / \mathrm{mL}$ of MCP solution were analyzed.

Table 4 - Results of the recovery assay

\begin{tabular}{|c|c|c|c|c|c|}
\hline \multirow{2}{*}{$\begin{array}{l}\text { Mass added } \\
{[\mathrm{mg}]}\end{array}$} & \multirow{2}{*}{$\begin{array}{l}\mathbf{M}_{\mathrm{MCA}} \text { recovered } \\
{[\mathrm{mg}]}\end{array}$} & \multirow{2}{*}{$\%$ Recovered } & \multirow{2}{*}{$\begin{array}{l}\% \text { Recovered } \\
\text { average }\end{array}$} & \multicolumn{2}{|l|}{ Precision } \\
\hline & & & & Parameter & Value [mg] \\
\hline 1.00 & 0.984 & 98.36 & \multirow{3}{*}{98.82} & $\mathbf{M}$ & 0.988 \\
\hline 1.00 & 0.997 & 99.75 & & SD & 0.008 \\
\hline 1.00 & 0.984 & 98.36 & & RSD\% & 0.811 \\
\hline 2.00 & 2.024 & 101.21 & \multirow{3}{*}{100.49} & $\mathbf{M}$ & 2.001 \\
\hline 2.00 & 1.976 & 98.78 & & SD & 0.024 \\
\hline 2.00 & 2.003 & 100.17 & & RSD \% & 1.217 \\
\hline 3.00 & 2.981 & 99.38 & \multirow{3}{*}{99.46} & $\mathbf{M}$ & 2.984 \\
\hline 3.00 & 3.002 & 100.07 & & SD & 0.017 \\
\hline 3.00 & 2.967 & 98.92 & & RSD \% & 0.585 \\
\hline
\end{tabular}

The recovery was 98.50 to $101.33 \%$, values that fall within the requirements set by USP and ANMAT (98.0-102.0\%) [2-3].

3.6.2 Comparison with the reference method

Results obtained using the official method (HPLC) is shown in Table 5. 
Table 5: Metoclopramide determination by HPLC-UV method.

RUN SIGNAL $\left.\begin{array}{ll}\text { CONC. } \\ {[\mathrm{mg} / \mathrm{mL}]}\end{array}\right) \begin{aligned} & \text { Recovery } \\ & {\left[\mathrm{mg}_{\mathrm{CFX}} / \mathrm{tablet}\right]}\end{aligned} \%$ Rec

\begin{tabular}{lllll}
\hline Std & 3051.6 & 1.00 & - & \\
1 & 3114.5 & 1.02 & 10.21 & 102.07 \\
2 & 3074.9 & 1.01 & 10.08 & 100.77 \\
3 & 3013.1 & 1.01 & 9.87 & 98.75 \\
4 & 3082.1 & 1.01 & 10.10 & 101.01 \\
5 & 3031.15 & 1.01 & 9.93 & 99.34 \\
6 & 3068.5 & 1.01 & 10.06 & 100.56 \\
\hline & & & M & 100.42 \\
& & & SD & 1.20 \\
& & & RSD\% & 1.19 \\
\hline
\end{tabular}

The spectrophotometric method was compared with the reference method using the $\mathrm{F}$ test for precisions and the $\mathrm{t}$ test for means, Table 6. Calculations were performed using Microsoft Excel ${ }^{\circledR}$ spreadsheet.

Table 6: Statistical comparison between proposed and reference methods.

Values in parentheses correspond to those tabulated for $\mathrm{p}=0.05$.

\begin{tabular}{|l|l|l|}
\hline Parameter & Spectrophotometric Method & HPLC-UV Method \\
\hline $\mathbf{X} \pm$ SD & $9.925 \pm 0.077$ & $10.042 \pm 0.123$ \\
\hline RSD\% & 0.776 & 1.225 \\
\hline $\mathbf{S}^{\mathbf{2}}$ & 0.00591 & 0.01510 \\
\hline F test & $2.554(5.050)$ & \\
\hline $\mathbf{t}$ test & $1.972(2.228)$ & \\
\hline
\end{tabular}

Statistically, it is found that there are no significant differences between the results obtained using the spectrophotometric method and the reference method for the determination of MCP, with a confidence level of $95 \%$.

\section{CONCLUSIONS}

The results obtained enable the application of this spectrophotometric methodology for the quantification of the active ingredient in pharmaceutical tablets containing metoclopramide as a single drug, with accuracy and precision comparable to the HPLC reference method, without interference from common excipients and within the range established by the USP and ANMAT. The spectrophotometric method offers several advantages such as shorter time analysis, lower cost and simplicity.

\section{ACKNOWLEDGEMENTS}

This research was supported by a grant co-financed by the General Secretary of Science and Technology of the Northeastern National University (UNNE) and the National Council of Scientific and Technical Research (CONICET) of Argentina, and with the collaboration of the Pharmaceutical Plant of Corrientes (PLAMECOR).

\section{REFERENCES}

[1] British Pharmacopoeia (Her Majesty's Stationary Office, London. 2009)[2] United States Pharmacopeia XXXII, National Formulary XXVII, US Pharmacopeial Convention, (Rockville, Maryland, 2008).

[3] Farmacopea Argentina. Octava Edición. Administración Nacional de Alimentos, Medicamentos y Tecnología Médica (Imprenta del Congreso de la Nación, Buenos Aires, Argentina, 2012).

[4] D. Pitrè, and R. Stradi, Metoclopramide hydrochloride. In: K. Florey (Ed.), Analytical profiles of drug substances, 16 (San Diego, USA: Academic Press., 1987). 327 - 360.

[5] R. J. Prankerd, Profiles of Drug Substances, Excipients, and Related Methodology, 33 (Edited by H. G. Brittain, 2007).

[6] A. Korolkovas, Dicionário Terapêutico Guanabara 2012/2013(Ed. Guanabara Koogan, 2012). 
[7] C. P. Page, M. J. Curtis, M. C. Sutter, M. J. A. Walker, y B. B. Hoffman, Farmacología Integrada (Ed. Harcourt. España. 1998).

[8] Y. S. Chang, Y. R. Ku, K. C. Wen and L. K. Ho, Analysis of synthetic gastrointestinal drugs in adulterated traditional Chinese medicines by HPCE, J. Liq. Chromatogr. Relat, Technol. 23, 2000, 2009-2019.

[9] L. M. Ross-Lee, M. J. Eadie, F. Bochner, W. D. Hooper and J. H. Tyrer, Electron - capture gas chromatographic assay for metoclopramide in plasma. J Chromatgr, 183(2), 1980, 175-184.

[10] O.A.Farghaly,M.A. Taher,A.H.Naggar,andA.Y.El-Sayed, Square wave anodicstrippingvoltammetric determination of metoclopramide in tablet and urine at carbon paste electrode, J. Pharm. Biomed. Anal, 38, 2005, 14-20.

[11] Z. H. Wang, H. Z. Zhang, S. P. Zhou, and W. J. Dong, Determination of trace metoclopramide by anodic stripping voltammetry with nafion modified glassy carbon electrode, Talanta, 53, 2001, 1133-1138.

[12] G. A. E. Mostafa, PVC matrix membrane sensor for potentiometric determination of metoclopramide hydrochloride in some pharmaceutical formulations, J. Pharm. Biomed. Anal, 31, 2003, 515-521.

[13] N.A.Al-Arfai, Flow-injection chemiluminescent determination ofmetoclopramide hydrochloride in pharmaceutical formulations and biological fluids using the $\left[\mathrm{Ru}(\mathrm{dipy})_{3} 2+\right]$-permanganate system, Talanta 62, 2004, 255-263.

[14] B. X. Jia, Y. Q. Li, C. H. Liu, K. Li, and Y. X. Qi, Flow injection determination of metoclopramide based on KMnO4-HCHO chemiluminescence in a micellar medium, J. Lumin. 130, 2010, 2188-2191.

[15] S. Fang, Z. H. Wu, L. Zhang and L. Chao, Chemiluminescence determination of metoclopramide, Anal. Lett. 35, 2002, 1479-1489.

[16] X. Hun, and Z. Zhang, Electrogenerated chemiluminescence sensor for metoclopramide determination based on $\mathrm{Ru}(\mathrm{bpy})_{3} 2+$-doped silica nanoparticles dispersed in Nafion on glassy carbon electrode, J. Pharm. Biomed. Anal, 47,2008, 670-676.

[17] M. Buna, J. J. Aaron, P. Prognon and G. Mahuzier, Effects of $\mathrm{pH}$ and solvent on the fluorescence properties of biomedically important benzamides. Application to determination in drugs and in human urine, Analyst 121, 1996, 1551-1556.

[18] S. J. Wadher, P. R. Pathankar, M. Putanik, R. O. Ganjiwale and P. G. Yeole, Simultaneous Spectrophotometric estimation of paracetamol and metoclopramide hydrochloride in solid dosage form, Indian J. Pharm. Sci. 70, 2008, 393-395.

[19] M. Royo Herrero, A. Mellado Romero and J. Martinez Calatayud, Flow injection-spectrophotometric determination of metoclopramide hydrochloride, Talanta 47, 1998, 223-228.

[20] I. D.Silva, M. L.M. F. S. Saraiva,J. L. M. Santo and J. L. F. C. C. L. Lima, Sequential injection spectrophotometric determination of metoclopramide in pharmaceutical preparations. Spectrosc. Lett. 40, 2007, 51-61.

[21] F. M. Abdel-Gawad, and N. M. El-Guindi, Spectrophotometric determination of metoclopramide and oxybuprocaine through ion pair formation with thiocyanate and molybdenum (V) or cobalt (II). Analytical Letters. 28(8), 1995, 1437-1447.

[22] F. Faridbod, M. R. Ganjali, S. Labbafi, R. Dinarvand, S. Riahi, and P. Norouzi, A New metoclopramide potentiometric membrane sensor for analysis in pharmaceutical formulation and urine: concerns to theoretical study Int. J. Electrochem. Sci., 4, 2009, $772-786$.

[23] A. El- Gendy, Spectrophotometric determination of metoclopramide via charge-transfer complexes, Spectroscopy Letters, 25(8), 1992, $1297-1313$.

[24] M. Iêda de Souza Silva, L. M. F. S. Saraiva, J. L. M. Santos and J. L. F. C. Lima, Sequential injection spectrophotometric determination of metoclopramide in pharmaceutical preparations. Spectroscopy Letters. Special Issue: Spectrometry and Automation, 40(1), 2007, 51 - 61.

[25] H. D. Revanasiddapa, B. J. Manju, A spectrophometric method for the determination of metoclopramide $\mathrm{HCl}$ and dapsone, J.Pharm.Biomed.Anal, 25, 2001, 631-637.

[26] Ö. Güzel, And A. Salman, Spectrophotometric determination of drugs having primary amine group with pdimethylaminocinnamaldehyde. Turkish J. Pharm. Sci. 4 (1), 2007, 31 - 39.

[27] H. D. Revanasiddappa and M. A. Veena, Sensitive spectrophotometric determination of metoclopramide hydrochloride and dapsone in bulk sample and dosage forms. Science Asia 32; 2006, 319-321.

[28] O. Z. Devi, K. Basavaiah, K. Basavaiah Vinay, and H. O. Revanasiddappa, Determination of metoclopramide hydrochloride in pharmaceuticals and spiked human urine through diazotization reaction. Journal of Food and Drug Analysis, 20(2), 2012, 454-463.

[29] H. D. Revanasiddapa, B. J. Manju, Spectrophotometric determination of some chemotherapeutic agents using acetyl acetone. Drug Development and Industrial Pharmacy, 28(5), 2002, 515-521.

[30] B. Resende Freitas and J. Fernandes Magalhães, Avaliação de xaropes contendo cloridrato de metoclopramida, pelo método de Bratton-Marshall. Brazilian Journal of Pharmaceutical Sciences. 41(2), 2005, 191 -197.

[31] H. D. Revanasiddappa, K. Kumar, and M. Bilwa,x. A facile spectrophotometric determination of nitrite using diazotization with p-nitroaniline and coupling with acetyl acetone. Mikrochim. Acta 137, 2001, 249-253.

[32] A. Alkhami, S. Masahi and M. Bohram, Spectrophotometric determination of nitrite based on its reaction with pnitroaniline in the presence of diphenylamine in micellar media, Bull. Korean Chem. Soc. 25, 2004, 1009-1011.

[33] J. Fan, Y. Chen, C. Ye, and S. Feng, Flow injection spectrophotometric determination of metoclopramide, Chinese Journal of Analytical Chemistry, 29(2), 2001, 217-218.

[34] Q2 (R1) - ICH. International Conference On Harmonization of Technical Requirements for Registration of Pharmaceuticals for Human Use, ICH Harmonized Tripartite Guideline, Validation of Analytical Procedures: Text and Methodology, Complementary Guideline on Methodology, dated 06 November 1996, incorporated in November 2005, London.

[35] N. J. Miller, J. C. Miller, Estadística y quimiometría para química analítica. (Pearson Educación, Madrid, 2002). 